\title{
Role of penetrating grafts in herpetic keratitis
}

\author{
O. O. FFOOKS AND A. PIGKERING \\ St. James's Hospital, Leeds
}

Leigh (I966) stated that "at the present time possibly no corneal disease presents a wider variety of problems for keratoplasty than herpetic keratitis in all its forms". These problems involve the difficulty of handling friable waterlogged tissues, the decision whether to use a lamellar or full-thickness graft, the timing of the graft, and the ability to maintain a clear graft postoperatively. Nevertheless there is general agreement that keratoplasty is of value in cases of herpes simplex keratitis. Therapeutic keratoplasty is used for extensive recurrent dendritic ulceration, for spreading stromal herpes, and to remove chronically infected tissues by means of lamellar grafts. Tectonically grafts are used in herpetic keratitis in cases of perforation or threatened perforation of the cornea. Finally, opacified and quiescent cornea may be treated by optical penetrating grafts. It is felt that the dangers of penetrating keratoplasty are exaggerated and that in fact penetrating grafts produce less complications and difficulties and give better long-term results than lamellar grafts. With these points in mind a simpler direct approach has been made to this problem of herpetic keratitis in a series of sixteen cases (Table, overleaf):

(I) Penetrating grafts were used in all cases.

(2) With the exception of corneae with descemetocoeles or perforations, all grafting was carried out on clinically quiet eyes.

(3) Corticosteroids were administered in the same pattern in all cases irrespective of herpetic activity or vascularization.

(4) All donor corneae were removed and grafted to the host within I 2 hours of the death of the donor.

\section{Method}

Bacteriological cultures from the donor eyes are considered unnecessary and time wasting. In the time from their removal from the donor to the operation (maximum 12 hours) the eyes are stored in sterile liquid paraffin at $4^{\circ} \mathrm{C}$. The eyes are removed from their containers and washed thoroughly in sterile saline to remove all traces of liquid paraffin. A 7 or $8 \mathrm{~mm}$. trephine removes a full-thickness disc of donor cornea and the same trephine is used to remove a full-thickness disc from the affected patient's eye under general anaesthesia. In all cases the positioning of the trephine on the patient's cornea is such as to remove the maximum amount of affected tissue, and in attempting to achieve this the position of corneal vessels is ignored.

Direct edge-to-edge suturing is carried out using $7 / 0$ black silk - a procedure facilitated by the use of the operating microscope. The number of sutures required, depending on the need to achieve an airtight wound, varied from twelve to sixteen. Air is introduced into anterior chamber via the wound at the end of the operation and this is followed by the subconjunctival injection of $12.5 \mathrm{mg}$. prednisolone and the local instillation of chloramphenicol drops. A single pad covers the eye.

The first dressing is carried out after 24 hours, and atropine and chloramphenicol drops are instilled once daily. The patient is mobilized at this time. From the fifth postoperative day local 

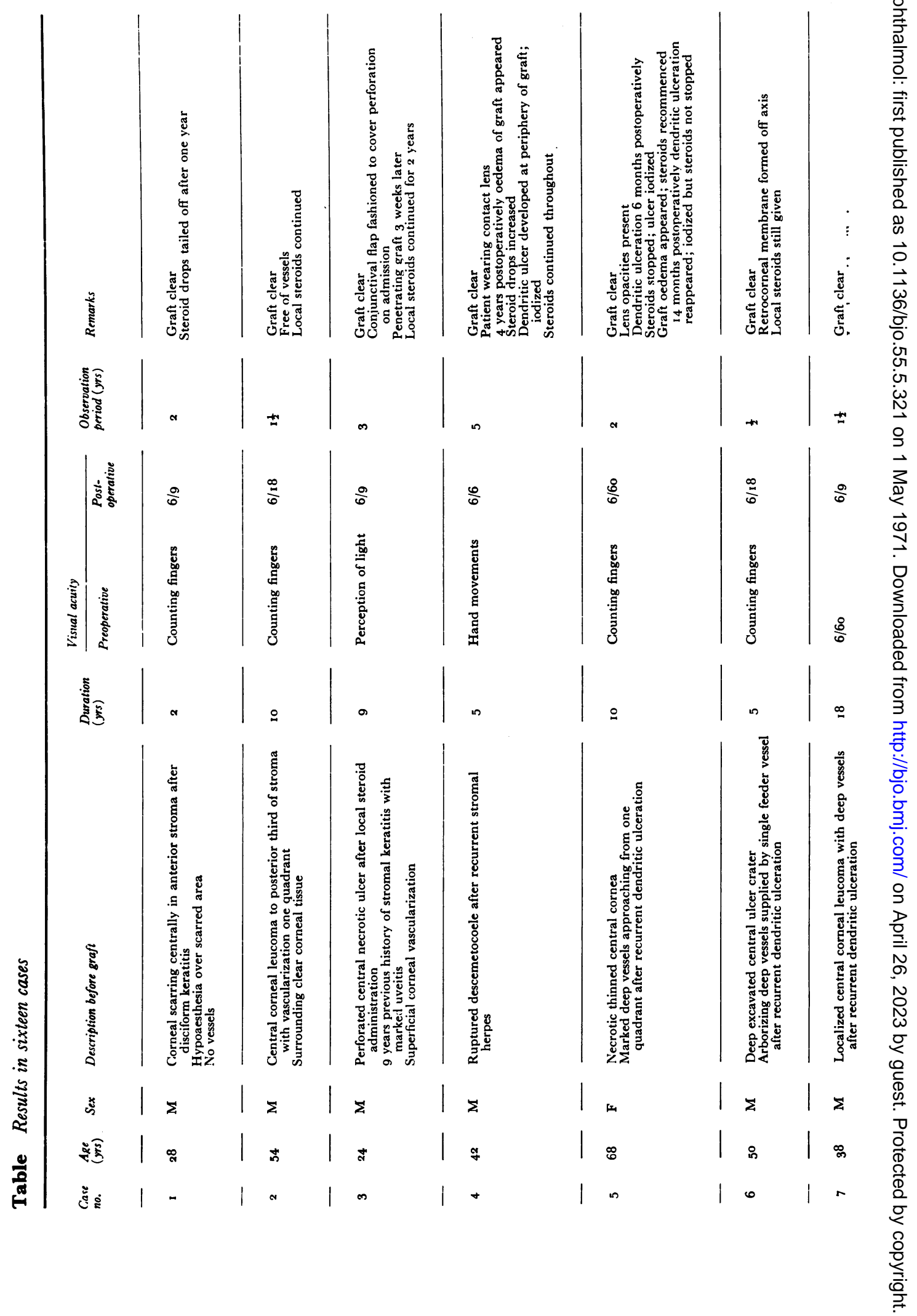

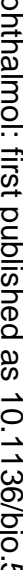



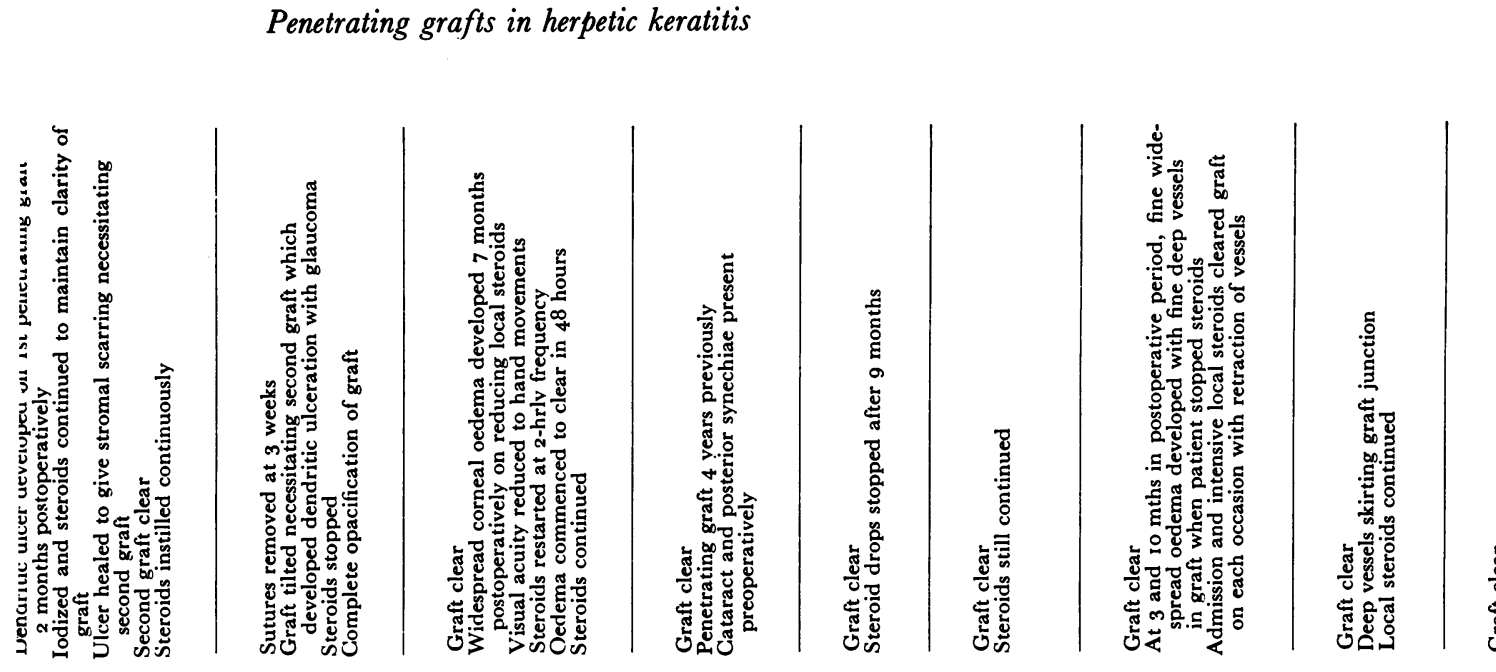

$\stackrel{\square}{\underline{m}}$
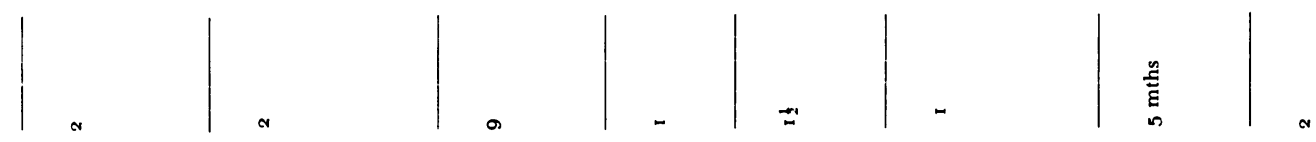

c
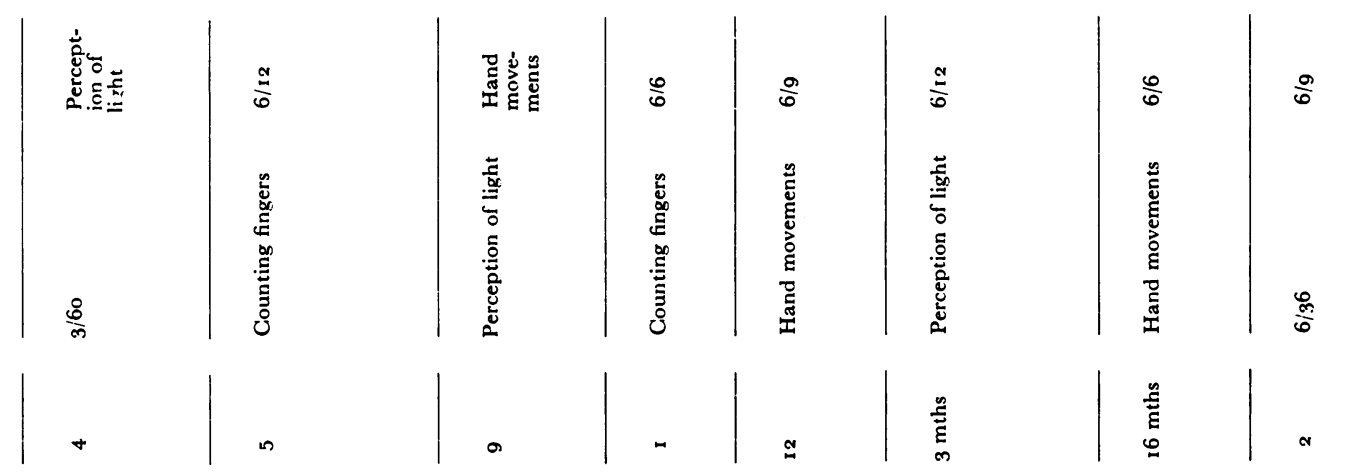

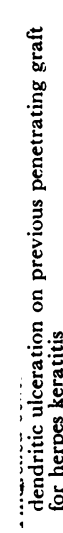
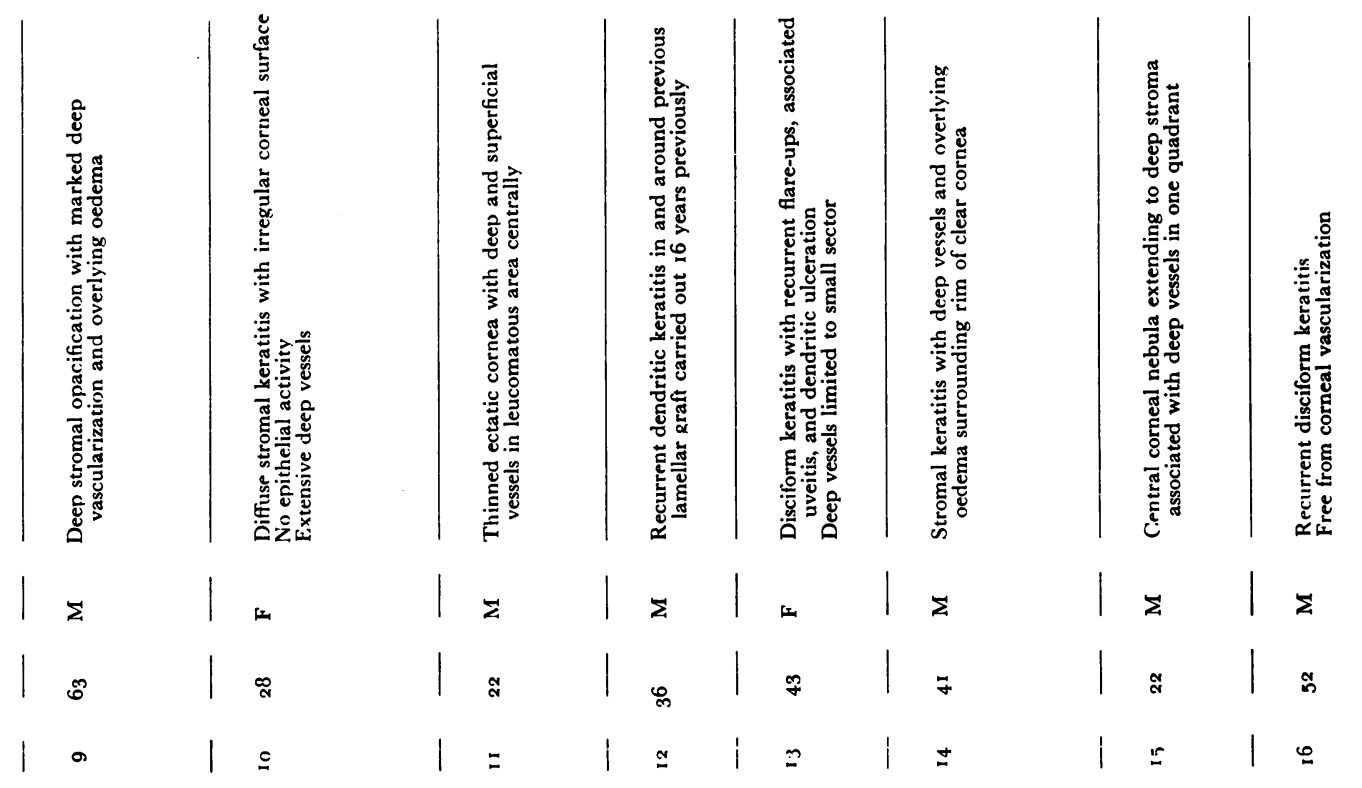
steroid drops are instilled four times daily; the antibiotic drops are continued until the tenth postoperative day and then stopped.

Alternate sutures are removed under local anaesthesia 4 weeks after the operation and the remaining sutures at 6 weeks. During this postoperative period atropine I per cent. and steroid drops four times daily are continued. In all cases local steroids were used for a minimum of 4 months and only then tailed off to twice daily instillation during the following 3 months and finally to zero in the next 2 months. However, special note was made, with regard to steroid administration, of those cases which showed marked vascularization at the time of operation or in which a large amount of affected tissue was left in the host cornea. The amount of steroid administration in these cases is directly related to the amount of vascularization. If any of these grafts developed signs of vascularization or oedema, drops were increased to 2 -hrly instillations and the patient was re-admitted to hospital. The oedema and vascularization is reversible in these cases and steroids are then continued indefinitely thereafter. Thus, with the exception of this type of case, steroids are administered locally from the time of the operation for a period of 9 months.

\section{Discussion}

It has been stated (Hogan, I958; Leigh, I 966) that penetrating keratoplasty carries wellrecognized complications which include failure of re-formation of the anterior chamber, iris prolapse, formation of anterior synechiae, development of glaucoma, and dislocation of the graft. In our experience with other penetrating grafts, supported by the results of this relatively small series, these complications should not occur. Indeed, with the exception of Case 9 in which the sutures were removed prematurely, none of the so-called well-recognized complications occurred, which supports our original decision to carry out penetrating keratoplasties on all these cases. Furthermore, it is felt that the technical difficulty in dissecting and suturing a lamellar graft outweighs its claimed main advantage of safety and that only in rare cases with superficial herpetic lesions does a satisfactory optical result occur.

The timing of the grafts presented no problem since they were carried out on clinically "quiet" eyes which for the purposes of this series meant the relative reduction of ciliary and conjunctival injection, an anterior chamber free of flare and cells, and a cornea where an attempt at epithelialization was being made. These findings, in conjunction with freedom from any marked pain, photophobia, or lacrimation, completed the picture. The time taken to achieve the quietened eye before perforating keratoplasty varied in each case but was never less than 2 months; some cases required a tarsorrhaphy to aid the healing processes. An exception to this waiting rule was made in Cases 3 and 4 in which perforation had occurred.

The pattern of steroid administration both in frequency and duration has produced very satisfactory results in maintaining graft clarity. It appears that continued use of local steroids is necessary for at least 9 months even in the face of frank dendritic ulceration which, if it appears, is treated by iodization - the results of which are demonstrated by Cases 4, 5, and 8. The other important point is that in cases with deep vascularization at the time of operation, or in which a large amount of affected host cornea remains, the frequency of local steroid administration must be increased if vascular invasion threatens the graft. Despite the sustained local steroid administration, retardation of wound healing and glaucoma have not presented any problems in the series.

The chief complications were:

(a) At operation None. No attempt was made to reduce the vascularization preoperatively, except by the use of local steriods. Any bleeding from vessels at operation was ignored. 
(b) Vascularization surrounding the graft When this appeared in the early postoperative stages its extension was controlled by increasing local steroids.

(c) Oedema of the graft This was generally related to the amount of vascularization present before grafting. It is always a danger even as late as 3 or 4 years after the operation.

(d) Recurrence of dendritic ulceration This was treated routinely by iodization, but steroid therapy had to be continued to maintain clarity of the graft.

In a very large general hospital with a high percentage of geriatric patients a supply of donor material is readily available to enable grafting as soon as possible after the death of the donor - how important a part this played in the production of these very satisfactory results is difficult to determine. The only other point to be made in this series is the fact that younger patients tended to produce a better result.

\section{Conclusions}

In this series of cases the decision to carry out corneal grafting was made on the grounds that there had been a loss of visual acuity below 6/1 8 with the eye in the quiet state. The exceptions were the cases of corneal perforation. Neither the visual acuity of the unaffected eye nor the degree of vascularization in the affected eye influenced the decision to operate.

Penetrating keratoplasty is a straightforward procedure from the purely technical point of view and is devoid of operative complications.

Steroids are required to maintain the clarity of the graft. An increased frequency of administration is required in proportion to the amount of vascularization at the time of operation and in cases in which a large amount of diseased host corneal tissue is left behind after grafting.

With the exception of Case 9 there has been total success in maintaining graft clarity using this approach, a fact which becomes more significant when it is remembered that four cases $(4,5,8$, and 9$)$ in this series had suffered a bout of dendritic ulceration in the postoperative period.

\section{Summary}

Results are presented of adopting a simple approach to grafting in sixteen cases of herpetic keratitis. Penetrating grafts were carried out in all patients and local steroids were used in the postoperative period.

\section{References}

hogan, м. J. (1958) Amer. F. Ophthal., 45, No. 4, pt 2, p. 106

LEIGH, A. G. (I966) "Corneal Transplantation", p. 224. Blackwell, Oxford

\section{Additional bibliography}

BuXton, J. N., APisson, J. G., and hoefle, f. B. (1969) Amer. 7. Ophthal., 67, 46

CASTROVIEJO, R. (1950) Ibid., 33, 185 I

FINE, M. (1958) Ibid., 46, 67 I

HOGAN, M. J. (1957) Ibid., 43, No. 4, pt 2, p. 147

HUGHes, W. F. (1969) Ibid., 67, 46, 313

LEIGH, A. G. (1967) Trans. ophthal. Soc. U.K., 87, 45

MOORE, T. E., and ARONSON, s. B. (1969) Ibid., 89, 379

ORMSBY, H. L. (1958) Amer. F. Ophthal., 45, No. 4, pt 2, p. 179 